\title{
Erratum to: Snowpack shifts cyanobacterial community in biological soil crusts
}

\author{
ZHANG Bingchang ${ }^{1,2}$, ZHANG Yongqing ${ }^{1}$, ZHOU Xiaobing ${ }^{2}$, LI Xiangzhen ${ }^{3 *}$, \\ ZHANG Yuanming ${ }^{2 *}$ \\ ${ }^{1}$ Geographical Science College, Shanxi Normal University, Linfen 041004, China; \\ ${ }^{2}$ State Key Laboratory of Desert and Oasis Ecology, Xinjiang Institute of Ecology and Geography, Chinese Academy of \\ Sciences, Urumqi 830011, China; \\ ${ }^{3}$ Fujian Provincial Key Laboratory of Soil Environmental Health and Regulation, College of Resources and Environment, \\ Fujian Agriculture and Forestry University, Fuzhou 350002, China
}

Published online: 13 April 2021

(C) Xinjiang Institute of Ecology and Geography, Chinese Academy of Sciences, Science Press and Springer-Verlag GmbH Germany, part of Springer Nature 2021

\section{Erratum to: J Arid Land (2021) 13(3): 239-256 https://doi.org/10.1007/s40333-021-0061-x}

In this Erratum, we corrected the grant award numbers of funding "the National Natural Science Foundation of China (U2003014, 41977099, 419901134)" in the Acknowledgements section. The correction is the National Natural Science Foundation of China (U2003214, 41977099, 41901134).

The online version of the original article can be found under https://doi.org/10.1007/s40333-021-0061-x. 